Article

\title{
Sana: A Gamified Rehabilitation Management System for Anterior Cruciate Ligament Reconstruction Recovery
}

\author{
Tanaka Kungwengwe * and Richard Evans \\ College of Engineering, Design and Physical Sciences, Brunel University London, Uxbridge UB8 3PH, UK; \\ richard.evans@brunel.ac.uk \\ * Correspondence: kungwengwe@outlook.com
}

Received: 29 June 2020; Accepted: 14 July 2020; Published: 16 July 2020

\begin{abstract}
The anterior cruciate ligament (ACL) provides stabilization support for the back and forth motion of the knee joint. ACL ruptures account for 50\% of all sports-related knee injuries with approximately $76.6 \%$ of them requiring reconstructive surgery, necessitating long-term patient rehabilitation. Compliance with rehabilitation management programs, following ACL reconstruction, is fundamental for the successful restoration of the knee's kinematics and reducing the risk of secondary osteoarthritis. Existing recovery programs are often paper-based and require patients to perform exercises at home, unsupervised, resulting in a low level of self-efficacy; by promoting self-efficacy in home-based settings, rehabilitation outcomes can improve. This paper reports the design development of the Sana system, a mobile and wearable application that adopts behavioral design principles and gamification theory to improve long-term post-operative outcomes for ACL reconstruction recovery. A feasibility study was conducted from 15 October 2019-13 May 2020, employing the double diamond framework and a human-centered design approach (BS EN ISO 9241-210: 2019). Eighteen participants were recruited, including eight domain experts (in fields such as user experience design, human factors, and physiotherapy), and ten representative users who had undergone long-term rehabilitation for musculoskeletal injuries.
\end{abstract}

Keywords: rehabilitation; compliance; anterior cruciate ligament reconstruction (ACLR); range of motion (ROM); self-efficacy; behavioral design; gamification

\section{Introduction}

Anterior cruciate ligament (ACL) ruptures account for $50 \%$ of all sports-related knee injuries. Approximately $76.6 \%$ of them result in reconstructive surgery, requiring long-term patient rehabilitation [1]. ACL tears often occur in activities that involve sudden stops or changes in movement and have profound effects on knee kinematics with recurrent knee instability as the main cause [2]. Anterior cruciate ligament reconstruction (ACLR) surgery is an integral aspect of treatment, but the economic repercussions are significant, with an estimated 15,000 primary ACL reconstructive surgeries performed in the UK annually, at a cost of $£ 63$ million [3]. To improve the success rate of recovery treatments, patients must remain compliant and perform exercises correctly. Failure to do so increases the chances of secondary knee osteoarthritis within 10-15 years post-surgery [4].

The digital health device market for ACLR rehabilitation has grown exponentially in recent years. With the emergence of Healthcare 4.0, patient-oriented systems, using the automated capture of patient data and transparent sharing with healthcare providers, can lead to improved healthcare delivery [5]. In the context of home-based physiotherapy (HBPT), following ACL reconstruction, a technological shift from traditional paper-based methods of treatment to automated interventions has occurred, 
significantly improving physiotherapy services for both patients and caregivers [6]; however, there is an identified need for assistive interventions for post-ACLR recovery patients to ensure optimal recovery.

Non-compliance to HBPT is a significant problem prevalent among patients recovering from musculoskeletal (MSK) injuries, with yearly rates as high as 50-65\% [7]. High rates of non-compliance are attributed to the fact that caregivers in public and private healthcare settings continue to administer paper-based treatment procedures. Paper-based procedures fail to provide personalized care and user engagement and, as a result, present barriers to rehabilitation compliance and self-efficacy. Numerous digital rehabilitation interventions exist on the market (e.g., Tracpatch and Re.Flex) that assist in knee surgery rehabilitation, but these are predominantly targeted towards the recovery of total knee replacement surgeries and not ACL injuries. Existing rehabilitation systems typically use augmented reality (AR) and interactive smartphone dashboards to provide patients with real-time feedback on their performance during rehabilitation exercises. Further, they enable caregivers to monitor patients' progress and advise on exercises remotely. Data can also be captured by patients' self-reporting recovery outcomes.

Currently available products and services combine smart mobile applications with wearable hardware devices to allow exercises to be performed and remotely monitored in at-home environments. Through Internet of Things, wireless sensors and biometrics, physiotherapists and doctors can monitor the kinetic and kinematic movements of patients post-surgery. For example, ROMBOT (https://rombot.com/) connects patients with licensed physiotherapists in the United States to create personalized movement programs to assist in pain management, recovery, and the prevention of injuries. Similarly, CyMedica Orthopedics developed e-vive which delivers tele-rehabilitation services connecting clinicians with patients that are undergoing partial and total knee replacement. Gait Up (https://www.gaitup.com/), developed as a spin-off of the University Hospital of Lausanne and the Swiss Institute of Technology of Lausanne, employs sensors, algorithms, and biometrics to convert inertial sensor signals into meaningful motion insights. Finally, physiotherapists at Macquarie University in Australia developed the REPS Recovery Exercises system, a recovery exercise application that allows stroke patients to complete exercises at home as part of a self-maintenance rehabilitation program.

As digital technologies and connectivity improves, rehabilitation management service providers are embedding gamified elements into their core functionality, providing more appealing and personalized experiences to wider audiences. During rehabilitation, gamification provides intrinsic motivation to keep patients on track and allows for provision of immediate feedback, making the process more fun, enjoyable, and interactive. Although numerous products are available for post-surgery rehabilitation management, limitations do exist, including: interfaces tend to be overtly technical and system orientated; they often fail to consider self-efficacy principles mentioned by Magee et al. [8] and Henderson and Cole [9], based on motivation and positive re-enforcement in their interface design. Future ACL recovery systems must (1) measure the quality of patients' adherence to exercise instructions, (2) measure performance through monitoring the quality of pre-determined exercises, and (3) share patient performance data periodically with caregivers to assist in the creation of well-informed, timely treatment decisions. This paper reports on the design development of a HBPT system that aims to improve the long-term post-operative outcomes of ACLR surgery. The platform focuses on addressing phase 1 (initial rehabilitation), where patients are primarily expected to regain their baseline range of motion.

\subsection{Post-Operative ACLR Surgery}

The time taken to reach full recovery from ACLR surgery varies between patients but can take up to 12 months. During this time, patients are normally provided with a HBPT program, with exercises that are specific to their needs, considering the severity of knee damage and the level of activity a patient is hoping to reobtain [10]. Table 1 provides a breakdown of each phase of rehabilitation, as established by the Royal National Orthopaedic Hospital (National Health Service (NHS) Trust) [11]. 
Table 1. Rehabilitation guidelines for patients undergoing ACL reconstruction rehabilitation.

\begin{tabular}{|c|c|c|}
\hline Phase 1 & Phase 2 & Phase 3 \\
\hline $\begin{array}{l}\text { Initial Rehabilitation Phase } \\
\text { (Duration: } 2-6 \text { weeks) }\end{array}$ & $\begin{array}{l}\text { Recovery Rehabilitation Phase } \\
\text { (Duration: 6-12 weeks) }\end{array}$ & $\begin{array}{c}\text { Intermediate-Final } \\
\text { Rehabilitation Phase } \\
\text { (Duration: } 12 \text { weeks-1 year) }\end{array}$ \\
\hline $\begin{array}{l}\text { Achieve full range of knee } \\
\text { extension to } 120^{\circ} \text { flexion. } \\
\text { Minimal activity related } \\
\text { joint effusion. } \\
\text { Reduce requirement for } \\
\text { mobility aids as comfort, } \\
\text { swelling, and knee control } \\
\text { allows to achieve no } \\
\text { gait abnormalities. } \\
\text { Symmetry on ascending and } \\
\text { descending stairs. }\end{array}$ & $\begin{array}{l}\text { - Bilaterally equal } \\
\text { proprioception tests on single } \\
\text { leg stance. } \\
\text { Bilaterally equal strength of } \\
\text { hamstrings, hip adductors, } \\
\text { hip abductors, } \\
\text { and gastrocnemius. }\end{array}$ & 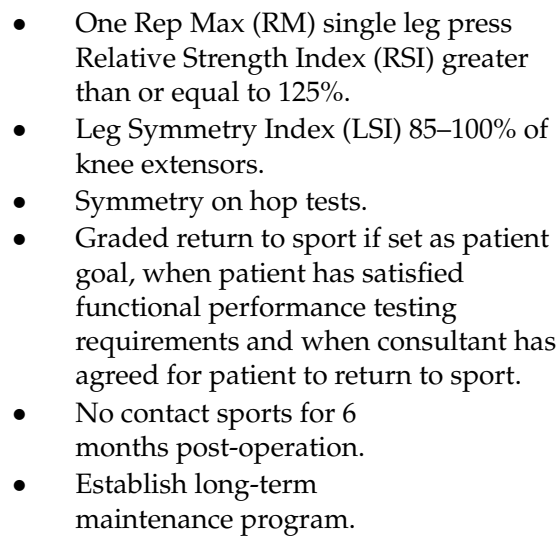 \\
\hline
\end{tabular}

\subsection{Related Work}

Gamification is defined as the use of game design features and elements in non-game contexts [12]. Extant research has supported the use of gamification in the rehabilitation process for musculoskeletal injuries $[13,14]$ and other health-related conditions $[12,15]$, especially to encourage engagement and increase patients' adherence to exercise programs. Qiu et al. [16] proposed Fun-Knee, a two-dimensional (2D) cartoon-based fishing game designed using UNITY engine. The authors identified that gamification can achieve significant levels of pain distraction, thereby increasing rehabilitation compliance. In their study, patients performed a series of cognitively demanding tasks that diverted their attention away from their injury. Patients could also set the exercise difficulty based on their needs. Egan et al. [17] established that pain and physical discomfort are significant barriers to exercise compliance and determined that pain distraction through gamification is one method that can be adopted to address this. Findings from Qiu et al. [16] showed that gamification methods are useful for enhancing rehabilitation compliance due to their motivating, progress-tracking, and goal-oriented nature. Further, Brown et al. [12] applied motivational principles and game elements to their study, including visualization of progress and automated goal setting activities to enhance engagement and participation. By incorporating these features, adherence and completion rates rose to $97 \%$. Several studies have also shown that the inclusion of concept-based goal setting increases patients' motivation [18,19]. Gunaydin et al. [18] considered three simple game scenarios where the patient accumulated stars according to the correctness of their movement. This feedback was observed to improve the motivation of patients; however, the clinical benefits of the system require further validation using biostatistical analysis before conclusive results can be drawn.

Clausen et al. [19] proposed the GenuSport application, a muscle training program that consists of a strength monitoring unit with three integrated sensors and two primary game modes: maximal strength and flight control. Direct performance feedback was provided after each game. Their findings show that $80 \%$ of patients had high levels of compliance, meaning that they trained at least once per day. During the study, none of the patients required face-to-face contact and were able to use the device autonomously after adequate instruction. However, the researchers described seeing an overall decrease in frequency of use during the study and attributed this to the two game modes not developing over time in difficulty. From this, it can be assumed that a limitation of gamification is its need to be continuously evaluated and further developed to maintain long-term engagement.

Qui et al. also expressed similar challenges with regards to sustaining patients' long-term engagement and the fear of exercises becoming routine after initial interest. Deacon et al. [20] proposed 
a system that utilized the existing architecture of Nintendo Wii Balance with the aim of improving balance controls to reduce the risk of falls in older patients. Feedback provided to the user was focused on positive reinforcement which occurred once the patient had completed an exercise. The benefits of this approach were that it allowed patients to understand when they had completed a task to the best of their ability. The key extrinsic motivational factor was the hope of improved quality of life from using the system. Their results showed a need to implement audible feedback; users stated that they would find this more stimulating and engaging. However, since basic ACLR rehabilitation exercises require the patient to remain in a specific position to ensure accurate knee angle detection, Wii platforms are not ideal for ACLR rehabilitation.

Overall, gamification, like other persuasive architectures has merit, if implemented in the correct manner [12,21]. However, current research has criticized gamification in the healthcare sector. For example, Deloitte [22] described gamification as 'just another over-glorified tech trend', while Bogost [23] considered it a quick fix adopted by innovators to increase and promote engagement. Brown et al. [12] stated that these criticisms likely derive from the belief that "features such as points and leader boards miss the essence and power of games as motivational techniques which have the potential to encourage behavior change or adherence to treatment programs positively". Their study outlined the importance of encouraging engagement to treatment rather than technology, and that designers should consider this when applying gamification methods to contexts where the intention is to alleviate suffering and improve well-being [24]. To date, few studies have implemented gamification strategies to address rehabilitation requirements, specific to ACL reconstruction recovery. Therefore, the aim of this paper is to report the development of mobile system intervention capable of improving long-term post-operative outcomes for patients following ACLR surgery.

\section{Methods}

To design the proposed system, a feasibility study was conducted over an eight-month period from 15 October 2019-13 May 2020. The double diamond framework was employed to model the investigation, as shown in Figure 1. This consisted of four phases: discover, define, develop, and deliver. Referring to the guidelines outlined in 'BS EN ISO 9241-210: 2019-Part 210 Human-centred design for interactive systems' allowed the authors to ensure that the project adhered to the strict design protocols outlined by the NHS for developing digital health systems [25].

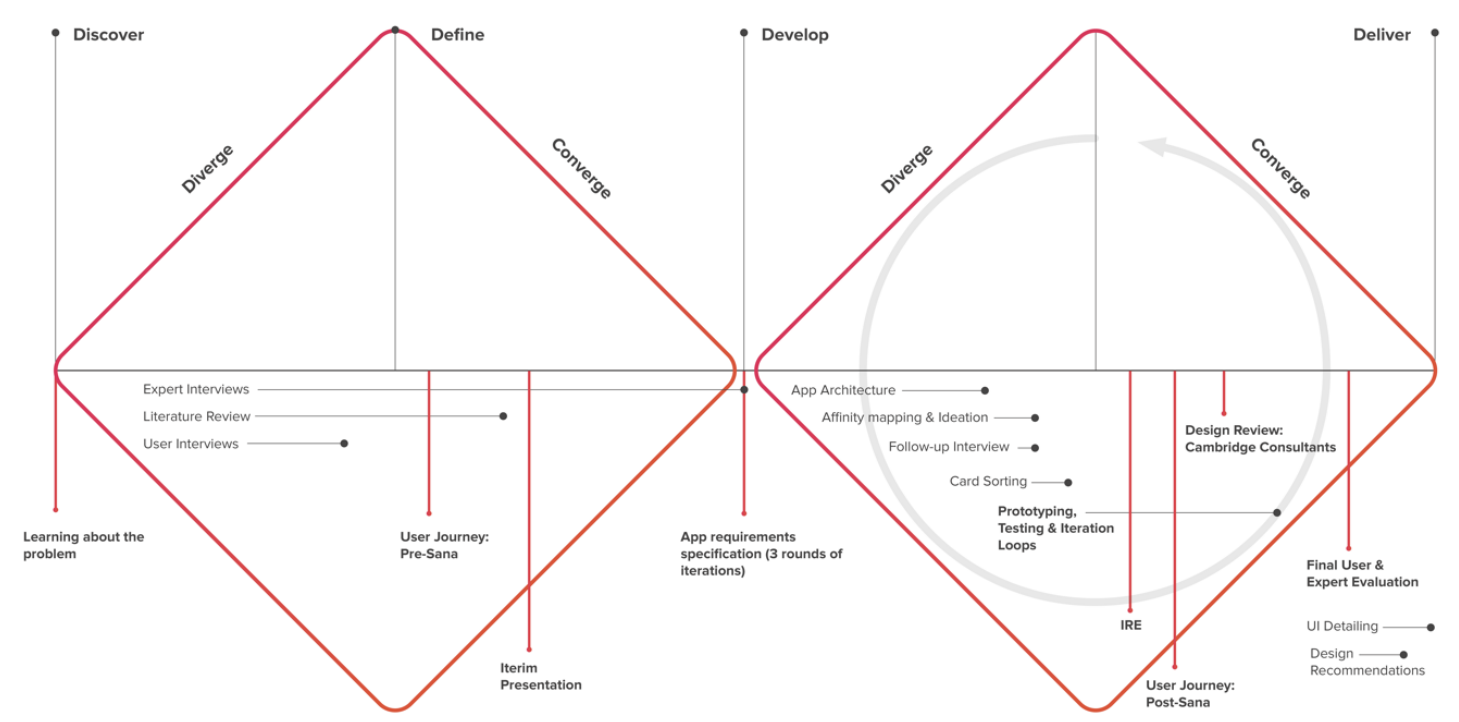

Figure 1. Study design based on the double diamond framework. 


\subsection{Discover and Define Phases}

First, two semi-structured interviews were conducted with one physiotherapist specializing in MSK rehabilitation at multiple stages of the design process. The first interview was conducted during the discovery phase and provided an initial understanding of ACL injuries and a basis for mapping out an initial patient-user journey called pre-Sana. The second follow-up interview was conducted during the define phase and helped validate design assumptions while addressing gaps in the authors' knowledge. The inclusion criteria for the expert interviews were a minimum of 7 years of professional or academic experience in MSK rehabilitation. Second, four representative patients were recruited for semi-structured interviews. This helped identify a range of pain points that patients experienced during HBPT, following total knee reconstruction procedures. The main inclusion criteria were users aged between 21 and 40 who had experienced MSK injury of the knee in the last year and had undergone long-term rehabilitation lasting between 2 and 6 weeks. The primary method used for data collection was voice recording, while insights were transcribed manually. NVivo 12 was used for data analysis. A best-fit approach was employed which ensured that insights were grouped based on their relation to the following themes: education, engagement with caregiver, self-efficacy, and support/education. This criterion was based on prior research conducted in the behavioral design and strong predictors of rehabilitation compliance [8].

\subsection{Develop Phase}

First, five open-moderated card sorting activities were conducted with representative patients. This user-centered design technique helped uncover the target users' expectations, thereby, allowing the authors to design a system infrastructure that was fit for purpose and delivered an optimal user experience. In the card sorting sessions, participants were tasked with organizing a set of 30 cards that corresponded with predetermined application features and functionalities into groups. The software used for data capture was OptimalSort, which provided qualitative insights that were presented using a dendrogram. Since only five participants were recruited for the study, the best merge method was used for data analysis; this method draws assumptions about more prominent clusters based on individual pair relationships. To obtain qualitative insights, participants were encouraged to think aloud and provide verbal justifications for their pairings. These insights were transcribed and analyzed manually.

Second, a design review with Cambridge Consultants, a technology consultancy with specialisms in medical device development, was conducted to validate the technical and design feasibility of the proposed system. Five participants were recruited who aligned with the specialisms required for the project delivery, including user experience (UX) research, UX design, human factors engineering, and software development. The design review was structured using the approach outlined by Harris [26] with insights categorized as challenges, ideas, likes, and questions.

Finally, online pilot usability tests were conducted over Zoom with two principle UX designers to fine-tune the study design and prototype before user testing. The inclusion criteria for these participants were a minimum of 7 years of professional experience in UX design for medical applications. To ensure that the results were appropriate to use in the final study, participants were recruited who also matched the criteria for the target user demographic of the system. However, since participants were not undergoing rehabilitation at the time of the study, context-setting and role-play instructions were provided during pre-study briefing. Participants were recruited from Cambridge Consultants who had participated in the design review study. The System Usability Scale method, proposed by Lewis and Sauro [27], was used for data analysis. Using the Fibonacci sequence (1-5), 'task criticality' and 'impact' scores were assigned to each task performed in the test. Issue frequency (\%) was calculated by dividing the number of occurrences by total participants. The last stage involved calculating the 'severity' of each issue by multiplying the three variables-criticality score, impact score, and issue frequency [28]. The results obtained helped inform decisions regarding usability issues during design and development. 


\subsection{Deliver Phase}

To conclude, one summative evaluation was conducted to assess the overall user experience of the proposed system against design specification and usability heuristics: visibility of system status, provide information feedback, recognition rather than control, aesthetics and minimalist design, and consistency and standards. The inclusion criteria were a minimum of 7 years of professional or academic experience in musculoskeletal rehabilitation. The interview was recorded, with insights being transcribed and analyzed manually.

\section{Results}

\subsection{Discover Phase}

The goal of the discovery phase was to establish potential bottlenecks in the patient-user journey. This required interviewing physiotherapists who specialized in MSK rehabilitation and users who had undergone total knee reconstruction surgery followed by long-term rehabilitation. In order to design a solution that effectively addressed users' primary needs, it was first essential to understand the challenges users faced from their point of view and empathize with their experiences. Four user interviews were conducted to gain insights into these challenges and pain points. Through analysis of interview findings, we categorized responses into three core challenges: (1) self-efficacy, (2) education, and (3) engagement with the primary caregiver. Further details are given below.

1. Self-efficacy: Issues related to self-efficacy resulted from patients having an unclear or no indication of progress and improvement during rehabilitation. Patients commonly stated that they often questioned the effectiveness of their therapy and had limited engagement with the exercises they were performing. There was an overall interest in being able to visualize the effects their therapy was having on their recovery and be able to track progress at each stage of rehabilitation. One interviewee stated, "It is easy to notice the pain, but I cannot see the improvement or progress".

2. Education: All interviewees stated that they were issued a paper-based treatment program detailing a summary of their injury and rehabilitation procedure. Users reported limited engagement with this information, reporting that the initial exercise demonstrations provided by their caregivers were more effective in reinforcing the correct exercise technique than static images. One interviewee noted that YouTube videos on exercises were beneficial. Overall, the key takeaway from this was that patients responded better to information that was presented in an engaging manner. Subsequent design concepts must explore ways that this can be achieved. One interviewee stated, "I had no level of engagement with my exercises ... I did not even know if what I was doing was correct."

3. Engagement with the primary caregiver: There was a shared view amongst users that they felt they had just been left to their own devices once discharged from the ward. Feedback would often be provided during patient follow-up; however, this was commonly described as either being 'monotonous', 'disengaging' or 'useless.' One interviewee remarked that something as simple as being told she was making small improvements by her caregiver would have been enough to motivate her to be persistent with therapy. In addition, one interviewee stated, "It would have been nice to have a follow-up with a healthcare specialist who understood the challenges I was having and gave useful advice. The feedback I was provided was often always the same".

\subsection{Define Phase}

The goal of the define phase was to consolidate the data collected during the discovery phase. A patient-user journey, called pre-Sana, depicting the fundamental pain points and design opportunities of the existing paper-based rehabilitation process was developed, as shown in Figure 2. 


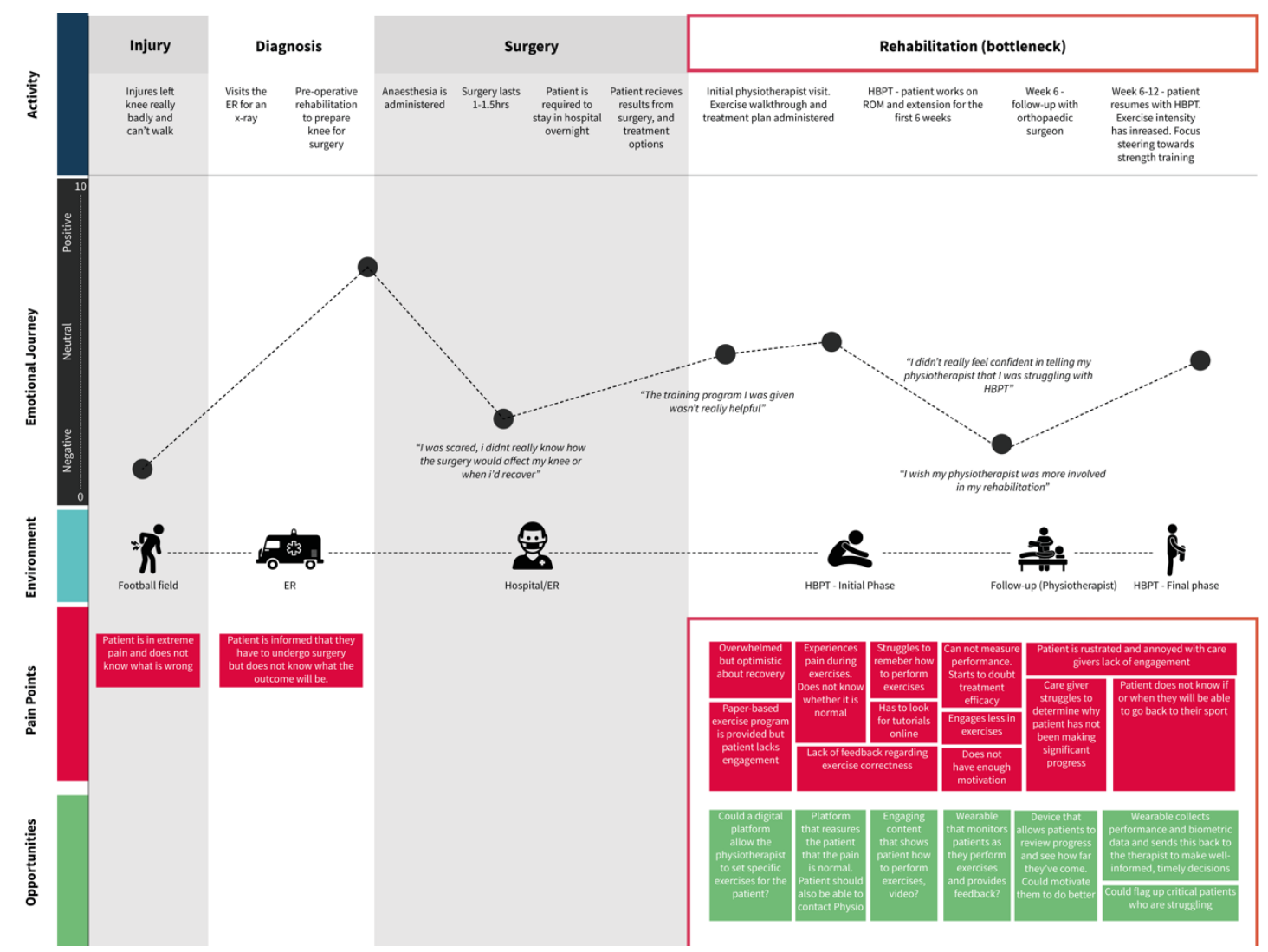

Figure 2. Current paper based anterior cruciate ligament reconstruction (ACLR) rehabilitation procedure: pre-Sana.

\subsection{Develop Phase}

The development phase focused on creating and refining the iteration flows and digital interface for the proposed system. Engagement with potential users and technical experts was maintained throughout the phase through rapid prototyping, iteration, and testing loops. This helped to ensure that assumptions were being continuously validated against the developed requirements specifications. The first stage in development involved the creation of a Unified Modeling Language (UML) diagram (Figure 3), to visually represent the system's information architecture along with its main actors, roles, and actions. The UML diagram was crucial in defining the initial high-level categories required for conducting the affinity mapping activity. Categories included view profile, therapy and exercises, dashboard, contact physiotherapist, and smart sleeve. These represented the features that patients would primarily interact with when navigating through the system. Considering that caregivers would have an external data collection dashboard, their engagement with the Sana app would primarily be when communicating remotely with the patient via the 'Contact' navigation item.

Once the system architecture was determined, an affinity mapping activity was conducted. The key research findings from the discovery phase were converted into a range of design ideas and potential system functions and features. These were then organized into the following established high-level categories: profile, therapy and exercises, dashboard, and contact. This activity was conducted to identify gaps in the authors' domain knowledge. A list of assumptions and questions was documented (Table 2) which was used to structure a follow-up interview with a physiotherapist (see Table 2).

- Profile: What information, if any, is a patient required to know regarding their injury? How often is a patient called up for follow-up treatment? What kind of advice or medication will a patient be given regarding pain and swelling management? 
- Therapy and exercises: Will a patient be provided additional exercise equipment? If so, what are some examples of this equipment? How often do patients engage in exercise? How much input, if any, should a patient have in terms of deciding what exercises? Should patients be given a range of alternative exercises to perform if they are struggling? Is diet something patients need to regularly monitor during rehabilitation?

- Dashboard: What are the different milestones that patients have during phase 1 of rehabilitation? What kind of data do caregivers need to collect about patients? How do patients currently determine whether treatment is working? What are the commonly used metrics to determine a patient's rate of recovery?

- Contact: How much flexibility do patients have in scheduling appointments themselves?

The follow-up interview helped answer the key questions and assumptions identified during the affinity mapping activity. Adjustments to the affinity map were made using insights gathered from the interview. This included disregarding features such as patient appointment scheduling, diet monitoring, and the ability for patients to choose their exercises from a list of approved exercises. From our findings, it was clear that exercise quality, exercise compliance, and pain levels were the most critical metrics caregivers use when completing assessment of whether a patient is successfully recovering.

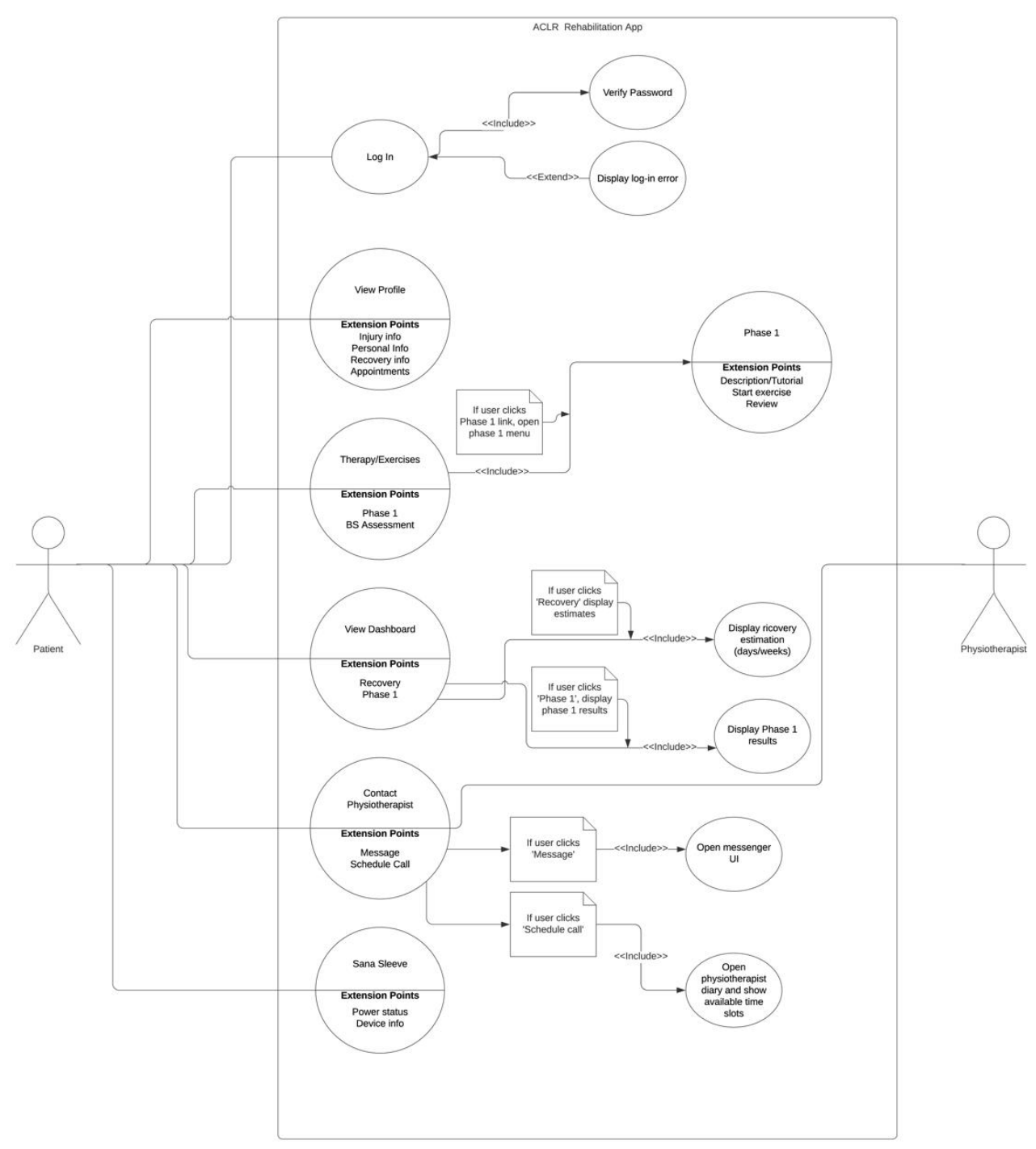

Figure 3. Unified Modeling Language (UML) diagram for the Sana system. 
Table 2. Results of the follow-up interview with the physiotherapist.

\begin{tabular}{l} 
Question \\
\hline What specific information is a \\
patient given regarding the nature \\
of their injury during initial \\
consultation?
\end{tabular}
for follow-up treatment?

\section{Patients will often be given}

information relating to their goals

for that rehabilitation phase and restrictions.

Physiotherapists see their patients more frequently during the acute rehabilitation phase (1), and less frequently after that.
How often do ACL reconstruction patients have to engage in physical therapy?
Patients need to perform exercises consistently during the acute rehabilitation phase.
Phase 1 is where caregivers need to ensure that the patient is doing everything correctly.

The type of exercises a patient engages in will depend on the type of injury, severity, and where the tissue is damaged. When physiotherapists are deciding on patient exercises, they need to think about the tissue, healing time frames, and clinical indicators (i.e., adequate quad strength, full range of motion and weight bearing).

\begin{tabular}{ll}
\hline What are the various types of & This varies depending on the type \\
equipment that patients will & of injury and the exercises that the \\
receive to support them with & physiotherapist wants patients to \\
exercises? & perform.
\end{tabular}

Does diet have an impact on a patient's rehabilitation success Yes.

None.

Diet is subjective. Your system should focus on rehabilitation exercises, improving efficacy, and rate? monitoring the quality of exercises performed.

The quantitative metrics we use are strength, range of motion, and swelling. Quality of movement is

What type of metrics need to be collected to show that a patient is recovering successfully?

Rotation, extension, bend, velocity, and power are important metrics. also important during exercises.

Are they weight shifting evenly? It is also useful to keep track of whether a patient's pain levels are going down.
Do patients schedule their own appointments or is this done by the healthcare provider?

What kinds of advice/medication will a patient be given regarding pain and swelling management?

Are the different phases of recovery fixed for every single post-ACL reconstruction patient?

Depends on the patient's level of injury. collaboration with the patient during the initial consultation.

Patients will be given advice an ice pack on their injury).
No. In private healthcare settings, physiotherapists tend to have a treatment plan; this involves mapping out when the patient will need to visit for follow-up care. Treatment plans are always set in regarding swelling management (i.e., how long they need to apply

None.

In the acute phase, it is important that the patient does not receive too much anti-inflammatory medication.

Patients should not push too hard during exercise. It is important to perform exercises correctly rather than too fast and not use correct form.
They cannot. They only find out about their performance during follow-up consultation
None.
How do patients monitor their own performance with rehabilitation? 
To determine the most appropriate content to be displayed on the system, we first acknowledged that content is often structured based on what makes sense to the designer, not to the end user. Sherwin [29] highlighted this as the number one usability problem in system design. For the proposed system, usability issues were mitigated by conducting a series of open-moderated card sorting activities. These assisted with the identification of target user demographics mental models and the establishing of the system infrastructure that was representative of these mental models. The data presented in Table 3 shows the key insights extracted from the dendrogram analysis in Figure 4. It highlights the features/cards that participants commonly grouped together and the labels they assigned each grouping during the card sorting activity.

Table 3. Card sort groupings.

\begin{tabular}{llllll}
\hline \multirow{2}{*}{$\begin{array}{c}\text { Cards/Potential } \\
\text { System Features }\end{array}$} & $\begin{array}{l}\text { Settings/Wearable } \\
\text { Device/FAQs }\end{array}$ & $\begin{array}{c}\text { Exercise/ } \\
\text { Rehabilitation/ } \\
\text { Therapy }\end{array}$ & $\begin{array}{c}\text { Profile/About } \\
\text { Me }\end{array}$ & Home Page & Dashboard \\
\cline { 2 - 6 } & $\begin{array}{l}\text { Instructions on } \\
\text { systems set-up }\end{array}$ & $\begin{array}{l}\text { Providing } \\
\text { feedback on my } \\
\text { pain levels }\end{array}$ & Personal details & $\begin{array}{l}\text { Setting exercise } \\
\text { reminders }\end{array}$ & $\begin{array}{l}\text { My exercise } \\
\text { performance }\end{array}$ \\
\hline & $\begin{array}{l}\text { Syncing my } \\
\text { Fitbit/fitness } \\
\text { tracker }\end{array}$ & $\begin{array}{l}\text { Guidance on how } \\
\text { to complete an } \\
\text { exercise }\end{array}$ & $\begin{array}{l}\text { Prescribed } \\
\text { medication and } \\
\text { dosage } \\
\text { information }\end{array}$ & $\begin{array}{l}\text { View my rewards } \\
\text { and achievements }\end{array}$ & $\begin{array}{l}\text { Adherence } \\
\text { levels to my } \\
\text { rehabilitation } \\
\text { program }\end{array}$ \\
\hline & $\begin{array}{l}\text { Detailed product } \\
\text { information (e.g., } \\
\text { battery life) }\end{array}$ & $\begin{array}{l}\text { Congratulatory } \\
\text { message that I } \\
\text { have completed } \\
\text { an exercise }\end{array}$ & $\begin{array}{l}\text { Summary of my } \\
\text { injury and } \\
\text { expectations of } \\
\text { recovery }\end{array}$ & $\begin{array}{l}\text { Adherence levels to } \\
\text { my rehabilitation } \\
\text { program }\end{array}$ \\
\hline
\end{tabular}

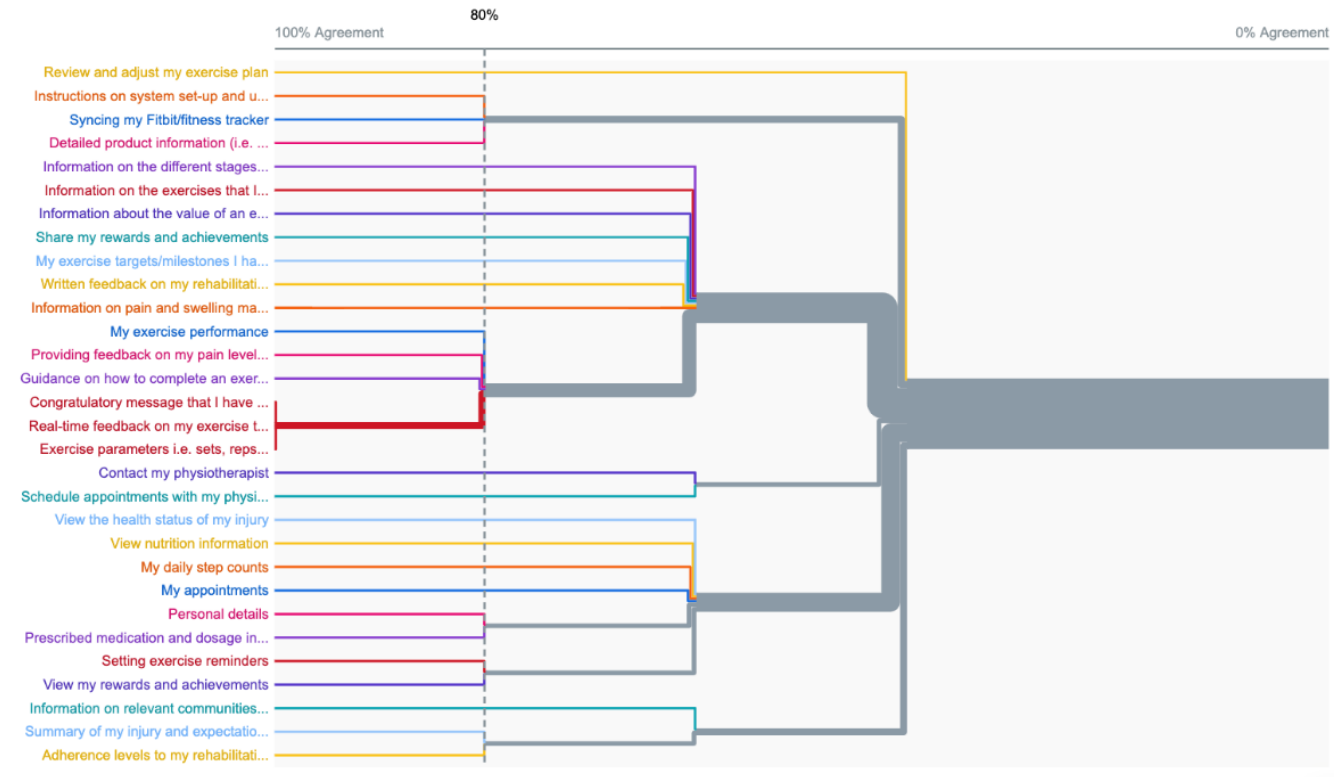

Figure 4. Dendrogram analysis.

\section{Patient User Journey: Post-Sana}

To design a new user journey that illustrates how users interact with the proposed system, a design review was conducted with Cambridge Consultants. This critique was crucial for validating the technical and design feasibility of the proposed system. It helped establish which areas required 
prioritization and refinement with subsequent development. Participants that specialized in UX design, UX research, human factors engineering, and software development participated in the critique. Insights from the affinity mapping and card sorting activities were instrumental for drafting the user interfaces for each stage of the user journey. The final user journey for the proposed system is shown in Figure 5.

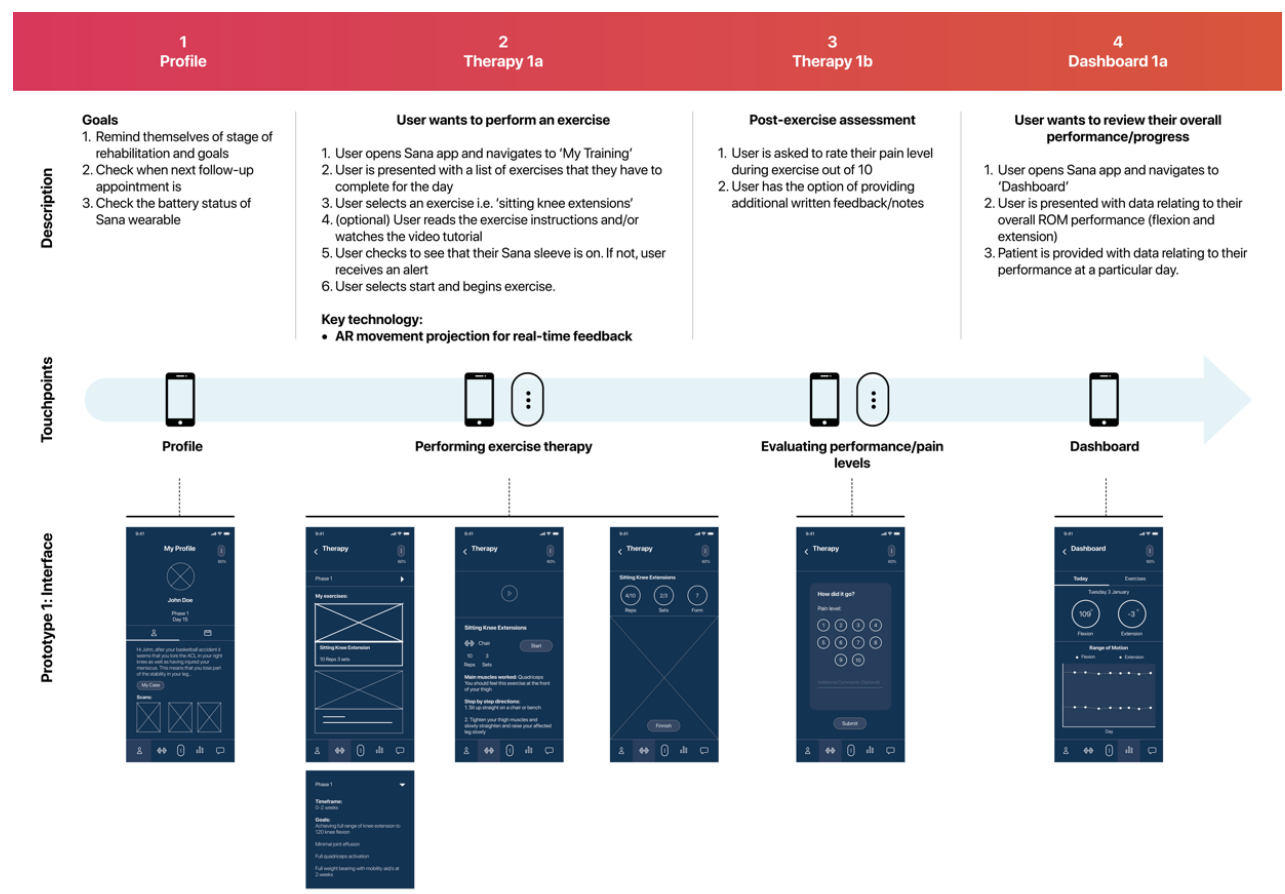

(a)

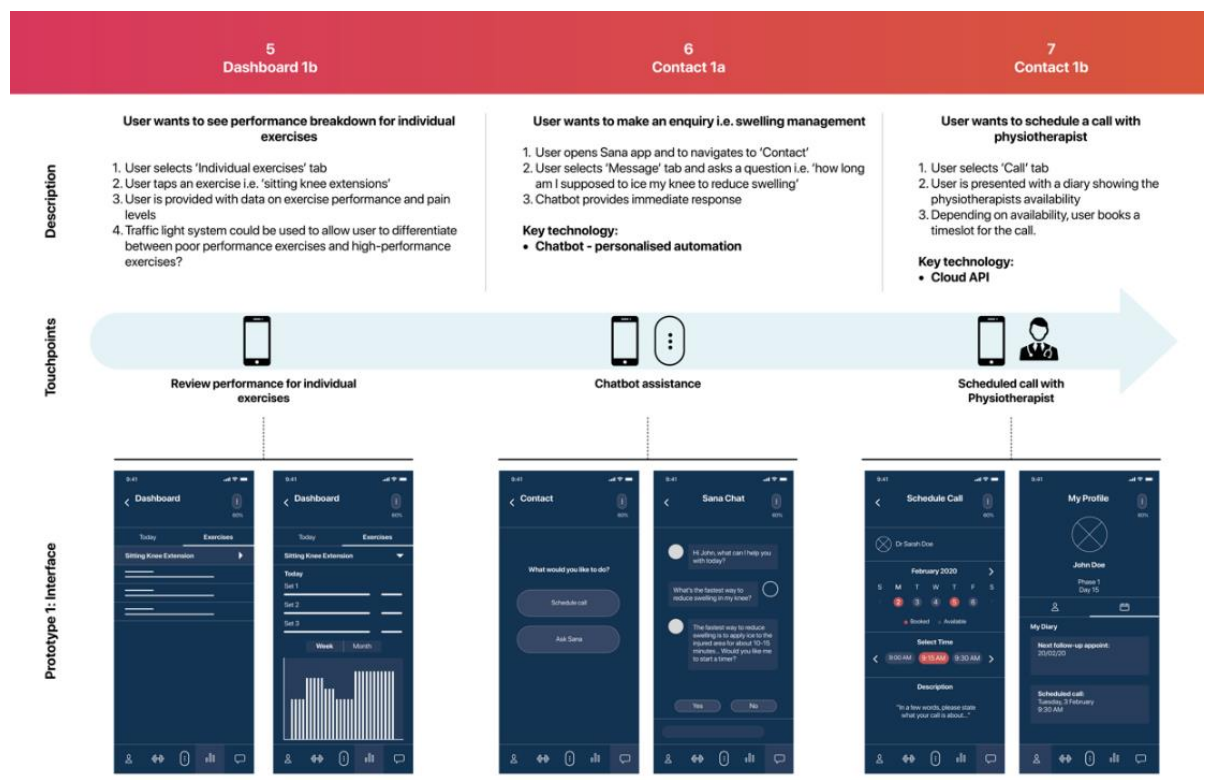

(b)

Figure 5. (a) User journey for interaction with the proposed system (steps 1-4). (b) User journey for interaction with the proposed system (steps 5-7). 
From the feedback collected during the design critique, shown in Table 4, it was clear that the focus areas for further development focused on the dashboard and exercise user workflows. As a result, the following actions were established, as shown in Table 4.

- Action 1: Dashboard workflow: Prioritize one dashboard feature for the final system (i.e., exercise reports, range of motion reports or adherence reports) and produce sketch concepts.

- Action 2: Exercise workflow: Refine exercise workflow with an emphasis on AR visualization, gamification, and positive feedback. Feedback on the system's interface was also provided, which was implemented in the next prototype iteration. The comments mainly centered around content hierarchy, navigation, and clarity of information presented within the interface.

Table 4. Feedback collected from the design critique.

\begin{tabular}{|c|c|}
\hline Challenges & Ideas and Improvements \\
\hline $\begin{array}{l}\text { - Getting patients to wear the device the same } \\
\text { way each time without avoiding sensor } \\
\text { displacement might be tricky. } \\
\text { How do you communicate exercise quality to a } \\
\text { patient in a way that is actionable? Is this even } \\
\text { technically possible? An alternative solution } \\
\text { may be to send the exercise quality metrics } \\
\text { directly to the caregiver who could use them to } \\
\text { teach the patient on how to improve } \\
\text { their technique. }\end{array}$ & $\begin{array}{l}\text { - } \quad \text { Reminder notifications for when to complete exercises. } \\
\text { - } \quad \text { Gxercise workflow is confusing and needs refinement. } \\
\text { but could be more clearly represented in the system. } \\
\text { - Research design trends used by sports-related apps (e.g., } \\
\text { 'Strava' and 'Adidas Running'). } \\
\text { - Could the wearable incorporate haptic feedback? } \\
\text { - Research data visualization techniques. } \\
\text { The purpose of the dashboard should be to } \\
\text { motivate patients. }\end{array}$ \\
\hline Likes & Questions \\
\hline $\begin{array}{l}\text { - The premise of the concept makes sense and } \\
\text { addresses the problem well. } \\
\text { - Gamification to encourage engagement } \\
\text { with exercises. } \\
\text { - Chat bot functionality is interesting, but feature } \\
\text { should be tested with other potential users. } \\
\text { Using AR to augment movement during } \\
\text { an exercise. }\end{array}$ & $\begin{array}{l}\text { - How will the device accommodate different body types? } \\
\text { (i.e., everyone's definition of quality is different). } \\
\text { - How do you communicate exercise quality to a patient in a } \\
\text { way that is actionable? } \\
\text { - System still looks very technical, where is the positive } \\
\text { reinforcement feedback? }\end{array}$ \\
\hline
\end{tabular}

Following the design critique meeting, the decision was made to prioritize exercise reports when developing the system's dashboard. The justification for this was that the feature directly aligns with the exercise workflow, which is the primary workflow used by patients. A series of sketch concepts were produced to illustrate the process of developing the workflow, as shown in Figure 6.

Similarly, a series of sketch concepts were produced to refine the exercise workflow and address some of the issues raised during the design review, relating to AR visualization, gamification, and positive feedback; these are illustrated in Figure 7. 

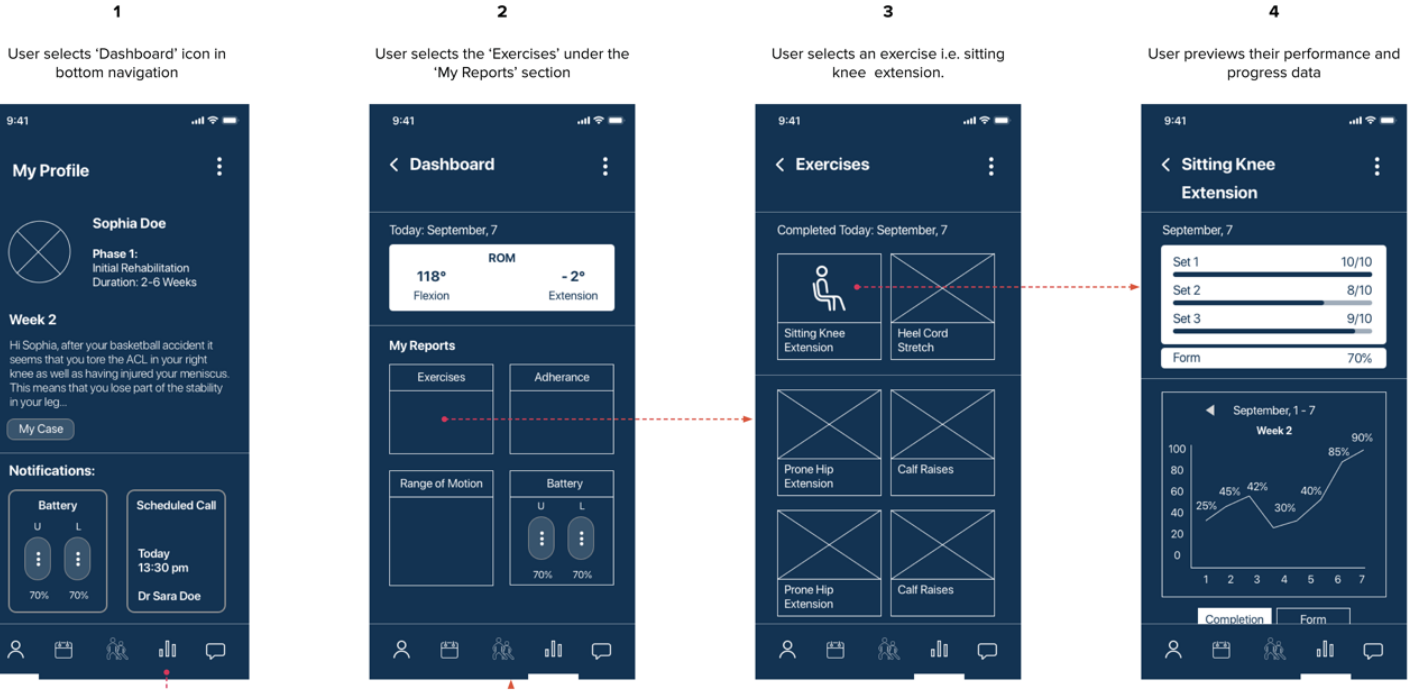

Figure 6. Dashboard workflow.

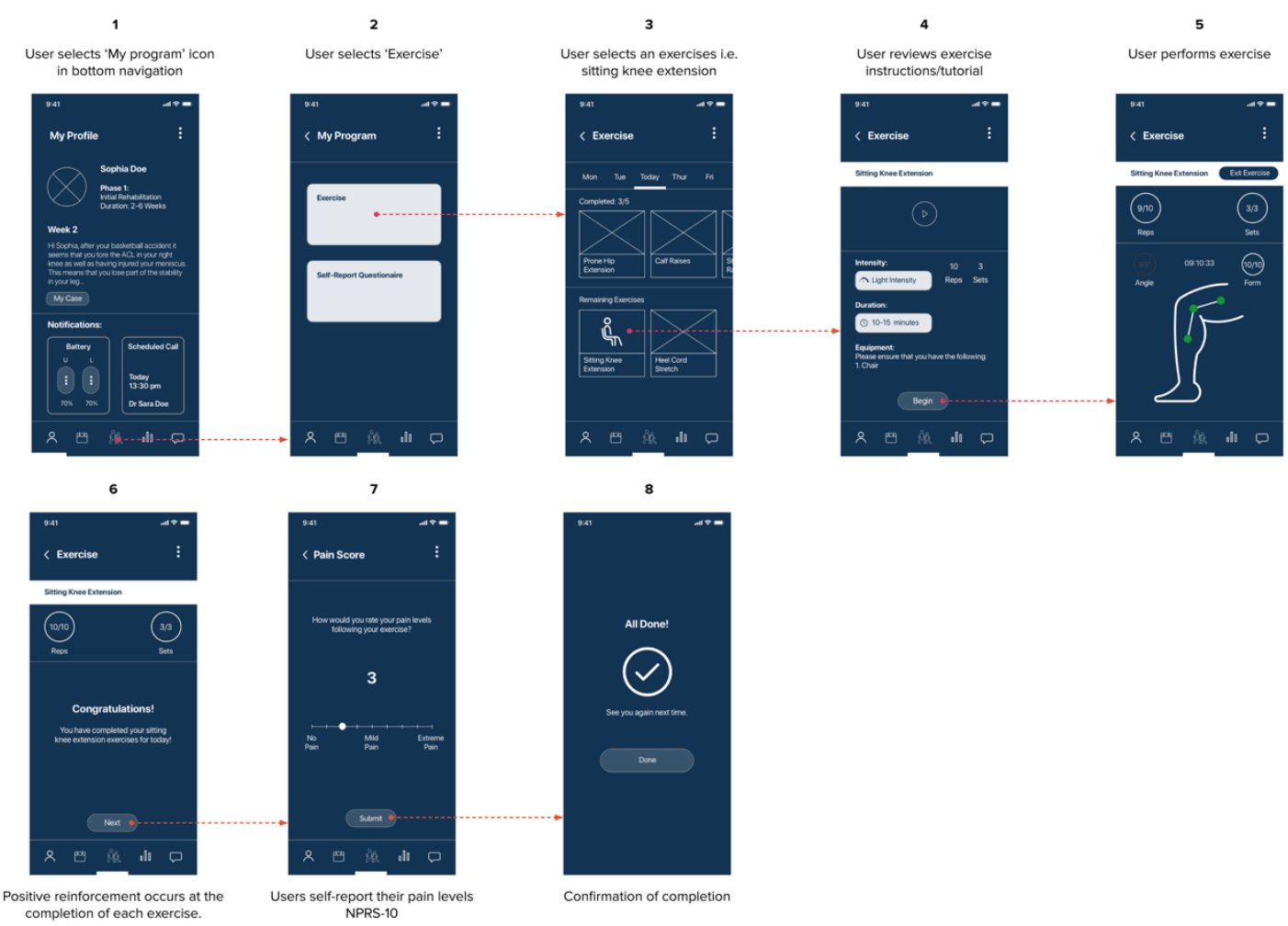

Figure 7. Exercise workflow.

\section{The Proposed System: Sana}

This chapter presents the developed system that incorporates the three key components of the Sana system, as presented in Figure 8. The system allows users to: (1) assess quality (i.e., measure the quality of adherence to exercise instructions at a specific time), (2) monitor performance (i.e., measure performance by monitoring the quality of a pre-determined set of exercises over time), and (3) share data (i.e., share performance data periodically with caregivers, helping them make well informed and timely treatment decisions). Figure 9 maps the user journey post-Sana development and illustrates the emotions experienced by users during system use. 


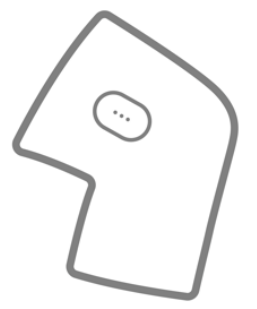

Sana Sleeve A rehabilitation sleeve that monitors knee kinematics during exercise and transmits data to the app
2

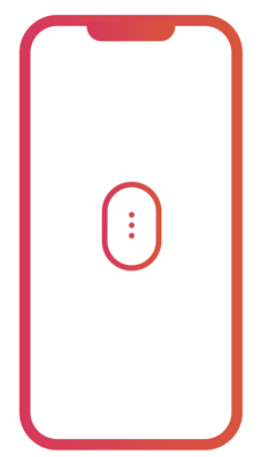

Sana App

A rehabilitation management app that

augments movement in real-time and

presents actionable insights to the patient.

Figure 8. The proposed Sana system. $\stackrel{2}{2}$

$\stackrel{3}{\text { System Setup }}$

Exercise Calibration

$$
\begin{gathered}
\mathbf{5} \\
\text { Subsequent Use } \\
12 \text { months }
\end{gathered}
$$

흘

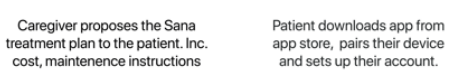

Exercise calibration is performed using the patients uninjured knee. This will maximum range of motion and establis

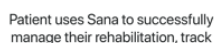
manage their rehabilitation, track
progress and communicate with their caregiver.
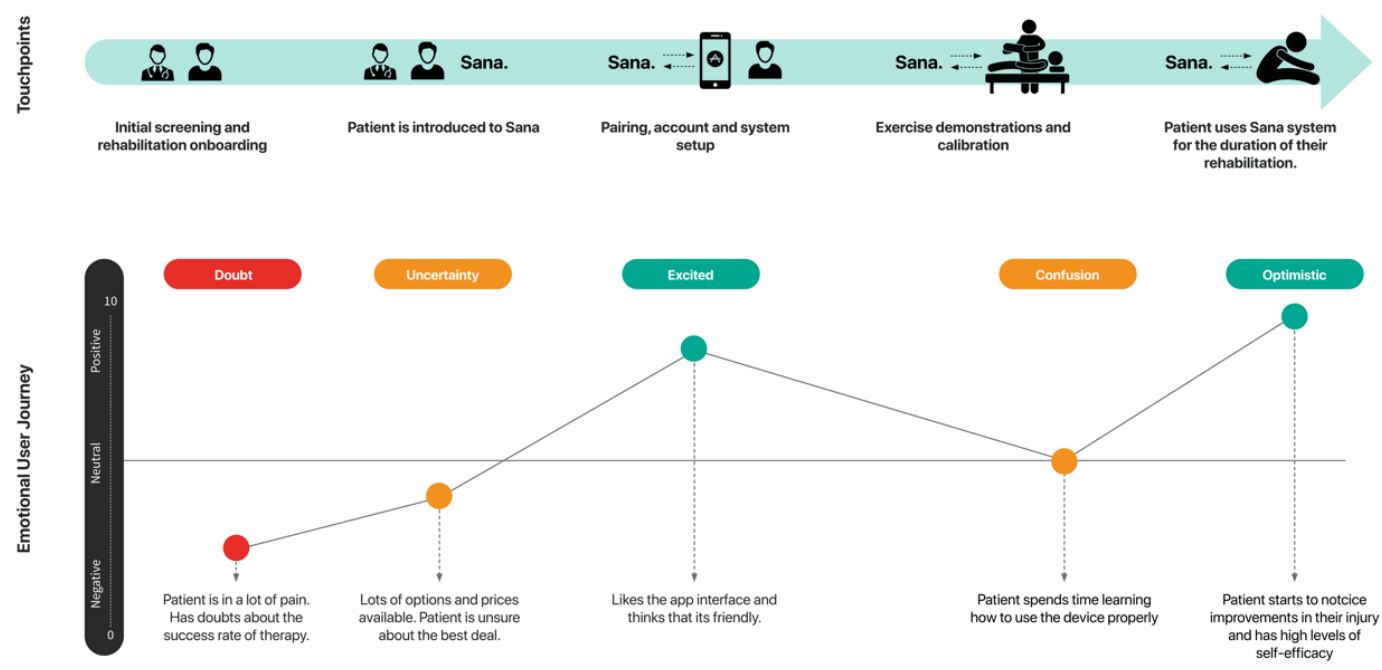

Figure 9. User journey map post-Sana development.

In Figure 10, screen prints of the developed system are shown. 

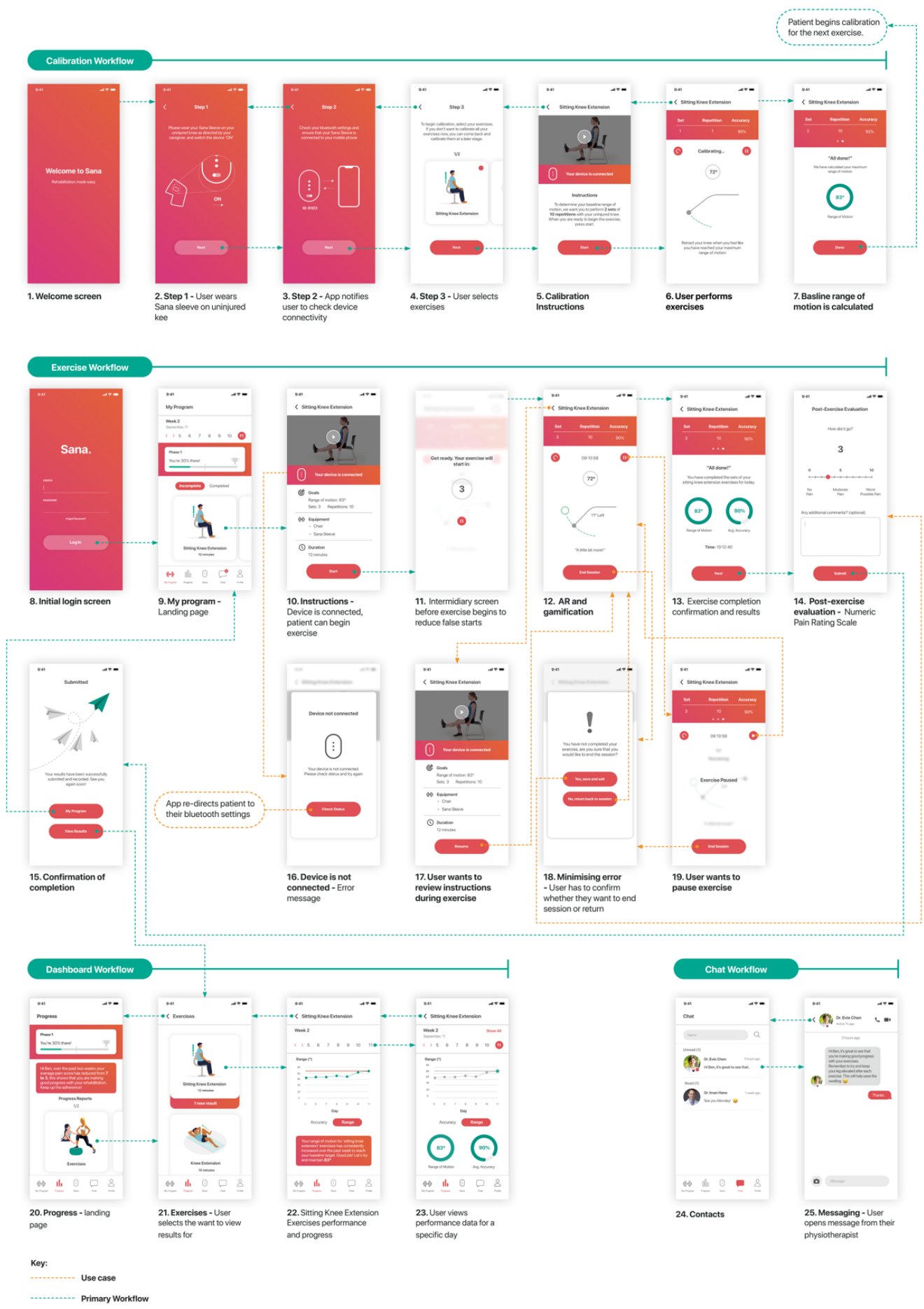

Figure 10. Screen prints of the developed Sana system.

\subsection{Exercise Calibration}

Setting realistic targets was deemed essential for promoting rehabilitation compliance. To ensure that each rehabilitation plan is optimally personalized to patients' specific needs and that realistic goals are set, patients calibrate their exercises using their uninjured knee during the service onboarding phase. The calibration activity is a crucial aspect of the overall user workflow as it helps physiotherapists to establish a patient's baseline. The baseline is then used as a metric measurement for treatment progression while providing patients with realistic rehabilitation goals. Figure 11 shows the calibration process. 


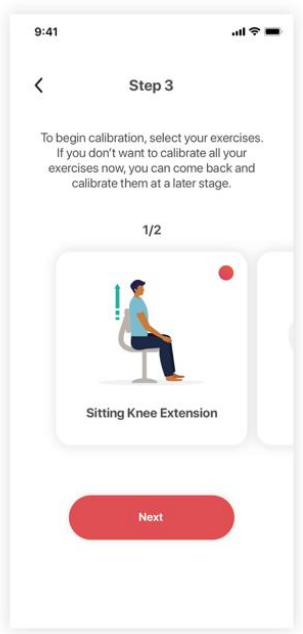

2

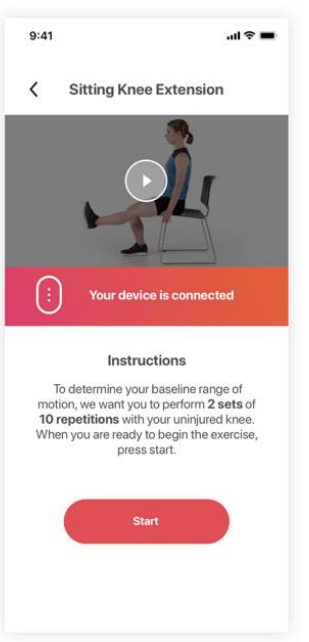

3

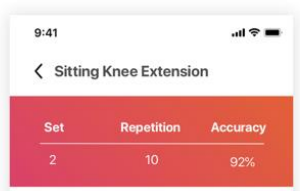

C Calibrating...
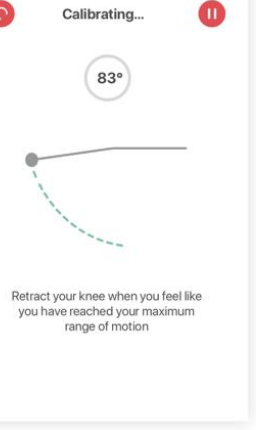

4

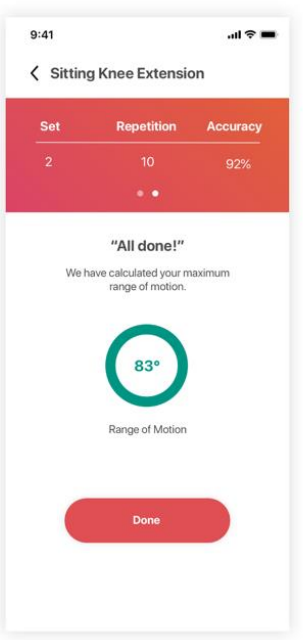

Figure 11. Calibration process.

\subsection{Integration of $A R$ and Exercise Gamification}

The Sana system builds on the fundamental principles of gamification through goal setting, allowing patients to be more engaged with their exercises. Testament to the validity of implementing this approach, Qiu et al. [16] highlighted how gamification can be an effective method for enhancing rehabilitation compliance due to its motivating, progressive, and goal-oriented nature. The Sana system adopts a simplified gamification approach to minimize the risk of patients pushing themselves too hard and worsening their injury. The patient has one goal: to reach the green circle, as shown in Figure 12, which is set based on their baseline maximum range of motion. Nielsen [30] stated that "sustaining a match between system and the real-world" is a critical usability heuristic; therefore, the Sana system is designed to mimic key aspects of real-life physiotherapy sessions through the use of audio feedback, as the patient progresses through their exercises. The benefits of this could be either positive reinforcement or reminding the patient to stop if they are experiencing pain.

1

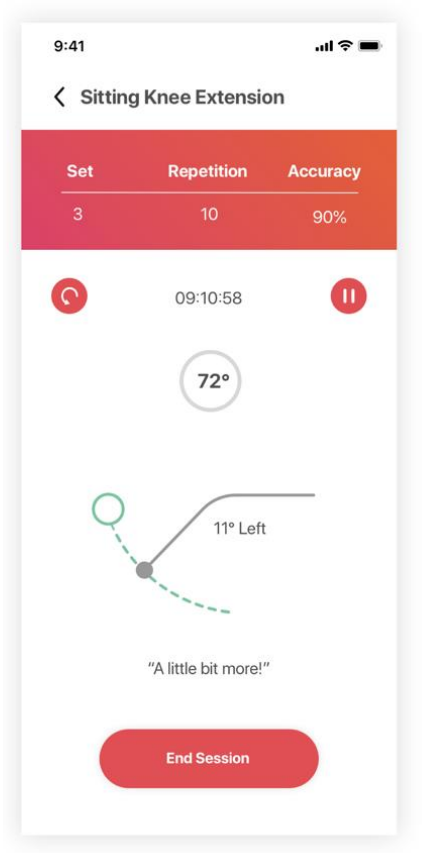

2

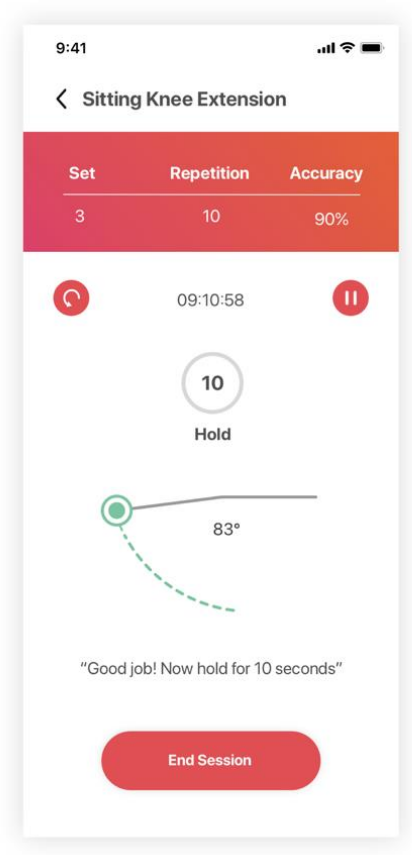

Figure 12. Screen print of the gamification element of the Sana system. 


\subsection{Progress and Performance Feedback}

During the development of the Sana system, the progress dashboard, as shown in Figure 13, had to be thoughtfully designed. While it may be easy to present progress and performance data to a patient through a digital interface only, this had to be achieved in such a way that would continuously keep patients motivated rather than overwhelmed. This is especially important considering that ACLR rehabilitation can take up to 12 months. Progress data are presented simply and unobtrusively via progress bars and colloquial syntax (e.g., "You're 30\% there!"). Through this approach, patients perceive the system as friendly and human-oriented, thereby increasing user engagement and long-term adherence to the rehabilitation program. Behavioral design and nudge theory are two fundamental pillars of the dashboard design. Positive reinforcement is used throughout to elicit feelings of personal accomplishment and to boost self-efficacy. Magee et al. [8] highlighted that positive reinforcement methods lead to higher levels of rehabilitation compliance; however, feedback provided by the primary caregiver is irreplaceable. The Sana system facilitates direct patient-caregiver communication by incorporating a chat facility. Magee et al. [8] also stated that patients who are aware of their clinicians' feelings towards their performance and progress are more likely to strive for positive rehabilitation outcomes.

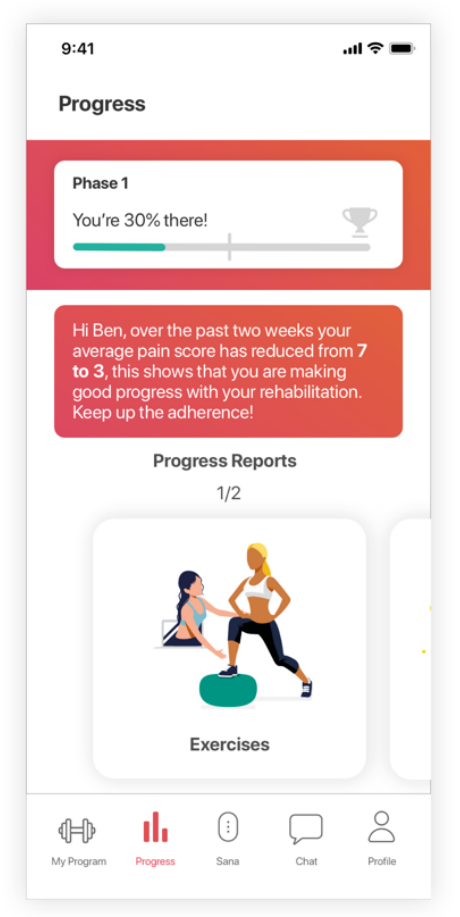

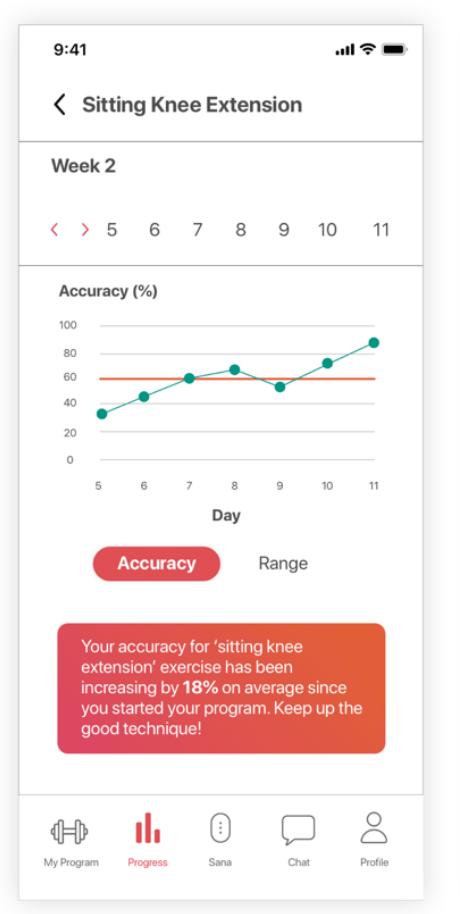

3

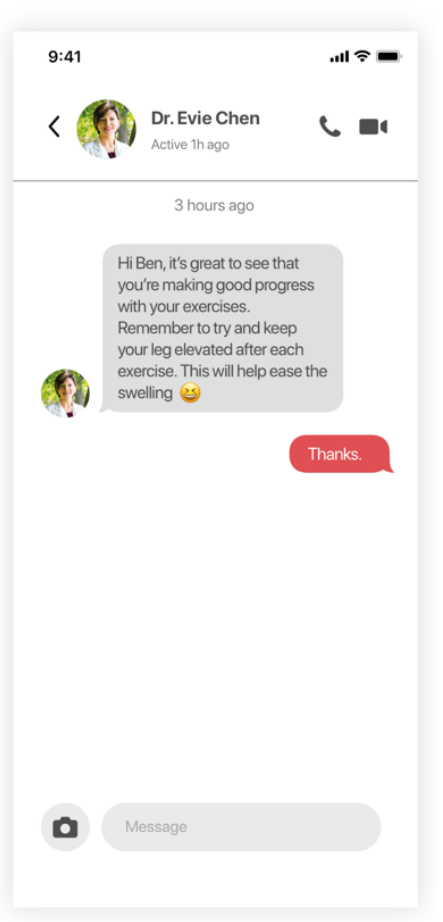

Figure 13. Screen print of the progress and feedback element of the Sana system.

Finally, a summative evaluation was conducted with an occupational therapist to assess the proposed system against the design specification and relevant usability heuristics. Overall, the concept was well-received. The participant stated that being able to review performance remotely was extremely beneficial for rehabilitation purposes. Regarding visual design, the therapist highlighted the simplicity, unobtrusive and friendly nature of the system as favorable characteristics which would lead to high adoption rates. Similarly, the participant did not experience any issues with navigation or performing set tasks, reflecting a good overall user experience. The participant agreed with the idea of using the uninjured knee to calibrate exercises to determine patients' baseline, describing it as "genius", and went on to suggest that they could see applications of this technology in other aspects of rehabilitation, such as shoulder and hand therapy. 


\section{Conclusions}

This paper reports the development of a mobile-based system that improves post-operative outcomes for patients that have undergone long-term rehabilitation for ACLR surgery. The authors developed Sana, a gamified rehabilitation management system with performance monitoring, data sharing, and quality assessment capabilities. Its content is based on rehabilitation guidelines established by the Royal National Orthopaedic Hospital, which incorporates rehabilitation concepts and treatment modalities that are an integral aspect of ACLR rehabilitation. The proposed system builds on the fundamentals of behavioral design and gamification theory to improve patient self-efficacy and engagement during rehabilitation. Findings show that target users found the proposed system to be convenient and unobtrusive, engaging, informative, easy to use, and user-friendly. Additionally, physiotherapists and primary caregivers stated that the proposed system can improve treatment administration and decision-making processes, provide a personalized rehabilitation experience for patients, and facilitate communication between patients and caregivers. These findings suggest that the proposed system is feasible and would make a positive contribution to ACLR rehabilitation and clinical practice.

\subsection{Study Limitations}

Of course, this study has several limitations. First, time represented a significant limitation. Due to the eight-month constraint of our project, it meant that only one deliverable was feasible, and a longitudinal clinical study could not be conducted to test the efficacy of the system in its intended context and quantify the error of using the system on the opposite leg; this will be conducted as future work. Second, due to limited human resource availability, the authors could not concentrate on all system elements during the time period of the project. Third, although most of the technology required to deliver the proposed system successfully was readily available, there were aspects of the process that would have benefited from additional technical resources, notably, eye-tracking software for user testing; this type of software is widely used in most software development projects and would have provided additional quantitative metrics on visual hierarchy, object weight, and problematic areas within the system's user interface. Using the opposite leg for calibration is a feature that was favored by therapists who participated in the study. Justification being, it aligns with current factors they consider when establishing patient specific rehabilitation goals. However, this feature could present challenges for patients with two injured limbs or those whose opposite leg is significantly weaker than the injured leg, pre-injury. To confirm its efficacy, the platform would need to undergo extensive user testing incorporating different user cases and scenarios. Likewise, it would need to be validated with a wider range of healthcare professionals.

\subsection{Future Developments}

Overall, the platform was positively received by target users, healthcare specialists, and technologists specializing in medical device development and design alike, which justifies the need to develop research and development further. Throughout our study, questions were raised regarding whether the simplicity of the implemented gamification concept would be enough to provide users with actionable visual feedback, informing them of whether they are performing their exercises correctly and accurately; determining this would require back-end software development. The next phase of the project will involve working with software engineers to develop the platform using Unity engine and testing a fully functional prototype; this will be reported in future research. Development efforts were primarily placed on the exercise, calibration, and progress review workflows, as these were seen as critical components of the proposed system. In the future, other key functionalities of the system, such as chat and my profile will need to be refined to complete the application's service. An integral part of assessing the overall efficacy of the proposed system will involve developing the Sana sleeve and clinician's dashboard and conducting a clinically controlled longitudinal study 
using the entire system (Sana app, sleeve, and dashboard). Developing the Sana sleeve will require establishing a team consisting of mechanical and material engineers who are specialists in this area. However, academic groups $[16,31,32]$ and commercial organizations, such as Loomia, have developed similar smart textile technologies that could be integrated, reporting high success rates. There is strong evidence to suggest that a smart textile approach is a potential future direction.

Author Contributions: Conceptualization, T.K.; methodology, T.K. and R.E.; validation, T.K.; investigation, T.K.; data curation, T.K.; writing — original draft preparation, T.K.; writing—review and editing, T.K. and R.E.; supervision, R.E.; project administration, T.K. All authors have read and agreed to the published version of the manuscript.

Funding: This research received no external funding.

Acknowledgments: The authors would like to thank Cambridge Consultants, the workshop technicians at Brunel University London for technical support provided during the research, and all those involved in the data collection exercises.

Conflicts of Interest: The authors declare no conflicts of interest. All subjects gave their informed consent for inclusion before they participated in the study. The study was conducted in accordance with the Declaration of Helsinki, and the protocol was approved by the Ethics Committee of Brunel University London (Refs: 19079-LR-Nov/2019- 21331-1 and 19079-LR-Nov/2019- 21331-2).

\section{References}

1. Joseph, A.; Collins, C.; Henke, N.; Yard, E.; Fields, S.; Comstock, R. A Multisport Epidemiologic Comparison of Anterior Cruciate Ligament Injuries in High School Athletics. J. Athl. Train. 2013, 48, 810-817. [CrossRef] [PubMed]

2. Essery, R.; Geraghty, A.; Kirby, S.; Yardley, L. Predictors of adherence to home-based physical therapies: A systematic review. Disabil. Rehabil. 2016, 39, 519-534. [CrossRef] [PubMed]

3. Comparison of the Clinical and Cost Effectiveness of Two Management Strategies for Non-Acute Anterior Cruciate Ligament (ACL) Injury: Rehabilitation Versus Surgical Reconstruction. Available online: https: //ichgcp.net/clinical-trials-registry/NCT02980367 (accessed on 25 April 2020).

4. Pietrosimone, B.; Seeley, M.K.; Johnston, C.; Pfeiffer, S.J.; Spang, J.T.; Blackburn, J.T. Walking Ground Reaction Force Post-ACL Reconstruction: Analysis of Time and Symptoms. Med. Sci. Sports Exerc. 2019, 51, 246-254. [CrossRef] [PubMed]

5. Tanwar, S.; Parekh, K.; Evans, R. Blockchain-based electronic healthcare record system for healthcare 4.0 applications. J. Inf. Secur. Appl. 2020, 50, 102407. [CrossRef]

6. Kungwengwe, T. Business Model. BA Industrial Design and Technology; Brunel University London: London, UK, 12 May 2020.

7. Adherence to Home Exercise Programs. Available online: https://www.physio-pedia.com/Adherence_to_ Home_Exercise_Programs\#cite_note-Wright-7 (accessed on 25 April 2020).

8. Magee, D.J.; Zachazewski, J.; Quillen, W.; Manske, R.A. Pathology and Intervention in Musculoskeletal Rehabilitation, 2nd ed.; Elsevier Inc.: London, UK, 2016; pp. 16-19.

9. Henderson, K.; Cole, J. The effects of exercise rehabilitation on perceived self-efficacy. Aust. J. Physiother. 1992, 38, 195-201. [CrossRef]

10. Anterior Cruciate Ligament (ACL) Reconstruction. Available online: https://www.bupa.co.uk/healthinformation/knee-clinic/treatment-and-care/anterior-cruciate-ligament-acl-reconstruction (accessed on 25 April 2020).

11. Rehabilitation Guidelines for Patients Undergoing Anterior Cruciate Ligament Repair (ACL). Available online: https:/www.rnoh.nhs.uk/services/rehabilitation-guidelines (accessed on 17 November 2019).

12. Brown, M.; O'Neill, N.; van Woerden, H.; Eslambolchilar, P.; Jones, M.; John, A. Gamification and Adherence to Web-Based Mental Health Interventions: A Systematic Review. JMIR Ment. Health 2016, 3, e39. [CrossRef] [PubMed]

13. Tannous, H.; Istrate, D.; Benlarbi-Delai, A.; Sarrazin, J.; Idriss, M.; Tho, M.; Dao, T. Exploring various orientation measurement approaches applied to a serious game system for functional rehabilitation. In Proceedings of the 38th Annual International Conference of the IEEE Engineering in Medicine and Biology Society, Orlando, FL, USA, 16-20 August 2016; IEEE: New York, NY, USA, 2016; p. 16395741. 
14. Idriss, M.; Tannous, H.; Istrate, D.; Perrochon, A.; Salle, J.; Ho Ba Tho, M.; Dao, T. Rehabilitation- Oriented Serious Game Development and Evaluation Guidelines for Musculoskeletal Disorders. JMIR Serious Games 2017, 5, e14. [CrossRef] [PubMed]

15. Mubin, O.; Alnajjar, F.; Jishtu, N.; Alsinglawi, B.; Al Mahmud, A. Exoskeletons with Virtual Reality, Augmented Reality, and Gamification for Stroke Patients' Rehabilitation: Systematic Review. JMIR Rehabil. Assist. Technol. 2019, 6, e12010. [CrossRef] [PubMed]

16. Qiu, Y.; Man Li, K.; Neoh, E.; Zhang, H.; Khaw, X.; Fan, X.; Miao, C. Fun-Knee ${ }^{\mathrm{TM}}$ : A Novel Smart Knee Sleeve for Total-Knee-Replacement Rehabilitation with Gamification. In Proceedings of the IEEE 5th International Conference on Serious Games and Applications for Health, Perth, Australia, 2-4 April 2017; IEEE: New York, NY, USA, 2017; p. 16946151.

17. Egan, A.; Mahmood, W.; Fenton, R.; Redziniak, N.; Kyaw Tun, T.; Sreenan, S.; McDermott, J. Barriers to exercise in obese patients with type 2 diabetes. QJM 2013, 106, 635-638. [CrossRef] [PubMed]

18. Gunaydin, T.; Arslan, R.; Birik, B.; Cirak, Y.; Durustkan Elbasi, N. A Surface Electromyography Based Serious Game for Increasing Patient Participation to Physiotherapy and Rehabilitation Treatment Following Anterior Cruciate and Medial Collateral Ligaments Operations. In Proceedings of the IEEE 31st International Symposium on Computer-Based Medical Systems, Karlstad, Sweden, 18-21 June 2018; IEEE: New York, NY, USA, 2018; p. 17936736.

19. Clausen, J.; Nahen, N.; Horstmann, H.; Lasch, F.; Krutsch, W.; Krettek, C.; Weber-Spickschen, T. Improving Maximal Strength in the Initial Postoperative Phase After Anterior Cruciate Ligament Reconstruction Surgery: Randomized Controlled Trial of an App-Based Serious Gaming Approach. JMIR Serious Games 2020,8, e14282. [CrossRef] [PubMed]

20. Deacon, M.; Parsons, J.; Mathieson, S.; Davies, T. Can Wii Balance? Evaluating a Stepping Game for Older Adults. IEEE Trans. Neural. Syst. Rehabil. Eng. 2018, 26, 1783-1793. [CrossRef] [PubMed]

21. Cugelman, B. Gamification: What It Is and Why It Matters to Digital Health Behavior Change Developers. JMIR Serious Games 2013, 1, e3. [CrossRef] [PubMed]

22. Tech Trends 2012: Elevate IT for Digital Business. Available online: https://www2.deloitte.com/content/dam/ Deloitte/au/Documents/technology/deloitte-au-technology-tech-trends-2012.pdf (accessed on 9 May 2020).

23. Exploitationware: On the Rhetoric of Gamification. From My "Persuasive Games" Column at Gamasutra. Available online: http://bogost.com/writing/exploitationware/ (accessed on 9 May 2020).

24. Gliddon, E.; Lauder, S.; Berk, L.; Cosgrove, V.; Grimm, D.; Dodd, S.; Suppes, T.; Berk, M. Evaluating discussion board engagement in the MoodSwings online self-help program for bipolar disorder: Protocol for an observational prospective cohort study. BMC Psychiatry 2015, 15. [CrossRef] [PubMed]

25. Digital NHS. Available online: https://digital.nhs.uk/ (accessed on 12 May 2020).

26. How to Conduct Design Review Meetings That don't Get Derailed. Available online: https://uxdesign.cc/ how-to-conduct-design-review-meetings-that-dont-get-derailed (accessed on 10 April 2020).

27. Lewis, J.; Sauro, J. Revisiting the Factor Structure of the System Usability Scale. J. Usability Stud. 2017, 12, $184-192$.

28. Turning Usability Testing Data into Action without Going Insane. Available online: https:/www.toptal.com/ designers/usability/turning-usability-testing-data-into-action (accessed on 25 April 2020).

29. Card Sorting: Uncover Users' Mental Models for Better Information Architecture. Available online: https://www.nngroup.com/articles/card-sorting-definition/ (accessed on 17 January 2020).

30. 10 Usability Heuristics for User Interface Design. Available online: https://www.nngroup.com/articles/tenusability-heuristics/ (accessed on 10 May 2020).

31. Haladjian, J.; Bredies, K.; Brügge, B. KneeHapp Textile: A Smart Textile System for Rehabilitation of Knee Injuries. In Proceedings of the IEEE 15th International Conference on Wearable and Implantable Body Sensor Networks, Las Vegas, NV, USA, 4-7 March 2018; IEEE: New York, NY, USA, 2018; p. 17681609.

32. Pereira, A.; Folgado, D.; Nunes, F.; Almeida, J.; Sousa, I. Using Inertial Sensors to Evaluate Exercise Correctness in Electromyography-based Home Rehabilitation Systems. In Proceedings of the IEEE International Symposium on Medical Measurements and Applications, Istanbul, Turkey, 26-28 June 2019; IEEE: New York, NY, USA, 2019; p. 18970423.

(C) 2020 by the authors. Licensee MDPI, Basel, Switzerland. This article is an open access article distributed under the terms and conditions of the Creative Commons Attribution (CC BY) license (http://creativecommons.org/licenses/by/4.0/). 